\title{
Panel Discussion on "Sustainable Development Goals”
}

The panel discussion was organized during the International conference EVF2019 to create awareness on Sustainable Development Goals from the Academic and Industry perspective. The panel discussion was led by Dr. Mohit Dubey CEO, AIC-MIT ADT Incubator Forum, Mr. Manojit Bose, Chief Knowledge Officer, Pune Smart City Development Corporation Limited, Mr. Nikhil Malhotra, Global Head of Innovation at Tech-Mahindra, Mr. Manish Mehta, Vice President \& Global Delivery Executive, Capgemini, Pune, Dr. Moumen Darcheriff, Director, ECAM-EPMI, France and Dr. M. EL GANAOUI, University de Loraine (France). Each panel Member had a debate, discussion, and put forth their contributions. The perspective of a few panel members is discussed so that the audience referring to the proceeding of EVF2029 are benefited at a larger scale.

\section{Innovation evolving between knowledge accumulation and knowledge creation}

When a society loses the memory of things, it loses its historical background and compromises its present and future. When a society loses the education of new generations, it loses its present and compromises its future. When it loses the ability to produce abstraction, It loses immediately any hope of the future.

The community of education anywhere in the world has the privilege to work with abstraction as an artist is handling the primitive matter, this privilege has to be merited after a longer period of listening, learning, making, doing and correcting errors. In any technology, the prediction - correction process is a part of the way from research to usual use.

The period when artificial intelligence has to assist human intelligence has passed. Today, a real menace of losing our ability to create an abstraction to facilitate our direction towards the good sense of things is permanently present and this increases the gap between the notion of technical smartness and humanist intelligence.

It is urgent to wait and to make a new skin allowing us better communication with earth and universe. This updated layer will be our better sensor to guide us in a short way to what is really needed by a future Village, City to guarantee, health, food, security, education, and happiness to their habitats. Hope and more realistic dreams will be the immediate consequence of such quality of life.

All the gadgets making our lives easier today come from hard work done in the last centuries on mathematics, physics, chemistry..etc. and the guidance has been working hard without waiting for any compensation and understanding 'how it worked' before 'why I'm working'.

It is evident that academic time and industrial time are not similar, and a dialogue has to be installed to create a common understanding. This can come from the elementary society's needs locally coupled to a global vision of the global system.

Pragmatic approaches, methods, philosophy can be discussed together to make a model of spirit economy taking advantage of the difference between the approaches in different success schools developing internationally.

Anywhere in the world, the time is a necessary remedy for any medication to work. While waiting for its effect, we should still encourage the exchange of methods and practices to make the dialog place in a city further and stronger. 
This round table made in Pune was an open space for a French-Indian and International dialogue with a convergence on our manner of seeing the future in such described spirit, this first meeting have to be reconducted periodically and illustrated by illustrative approaches made in our respective Universities and knowledge centers.

\section{Pr. M. El Ganaoui,}

\section{University of Lorraine, France}

Head of Research Group and in Charge of International cooperation, innovation and territory valorization in Institute Henri Poincaré of Longwy/Univ. Of Lorraine.

\section{EVF 2019 - Panel discussion - Intervention of M. DARCHERIF}

Sustainable development is a major concern for all economic, political and academic actors around the world. It is a complex human concept with multiple ramifications and impacts. It is a transgenerational problem that affects our present and the future of our children. Its complexity is also due to its multivariable character. It can be approached in different ways and admit various solutions.

From my point of view, as Professor and Academic Manager, facing the challenges and challenges of $S D$ requires acting on at least four levers:

- The first one, is to set a new global fighting disparities between countries. The sustainability is impossible if it's not Fair, Equitable and Responsible. We need to work together for building a better future. We share the planet, There is no south no north. More than a billion earthlings do not have access to food, while our planet has enough to feed 12 billion people.

- The second lever, is to Ensure perfect control of human resources, especially : energy, food and water. Technological advances are obviously needed, but it will be useless if political commitments are not made at the international level.

- The third one, is to Promote Innovation, Research and Entrepreneurship. We need to encourage our researchers to be part of an entrepreneurial approach, promoting the transfer of technologies and the incubation of innovative ideas.

- The last one is to raise awareness, to sensitize young people to the issues of tomorrow and above all to ensure them a high level education.

This last lever is fundamental. Why? Because the decision's makers of tomorrow are our current students. So, we must prepare them now. We have no time to loose. Our future engineers and managers must "think globally \& Act locally".

To do it, we need to adapt the content and the philosophy of our training, to connect our universities, and to promote students mobility. We must break the boundaries of knowledge. That's a big job easier said than done.

Our responsibility as trainers is complete. We need to act everywhere to better prepare our young people. 
Before ending my intervention, I want to give you some data concerning French education experience.

In France we have more almost 3 million students (undergraduate, graduate and post-graduate levels), almost 70 Universities, around 300 Engineering and Business Graduates schools, and more than 4000 high schools with three main sections (General one, technological one, and Professional one).

More than $20 \%$ of the French graduate schools prepare their students to deal with the main problematics of ecology and energy transition. That's good but not enough.

French high schools are more committed into Sustainable development. The most important technological section in France is called STI 2D (STI as "Sciences and Technologies for Industry". And 2D as "Développement Durable", which means Sustainable Development in French)

At ECAM-EPMI, Graduate school, more than $30 \%$ of the Master's courses are directly oriented towards sustainable development issues: "Energy transition", "Smart industry", and "Green Technologies". We have also a full degree dedicated to Energy and Materials of tomorrow.

\section{Prof. Moumen DARCHERIF,}

CEO of ECAM-EPMI, French Graduate School of Engineering, since 2001.

Vice-President of Paris-Seine University in charge of student live.

Senior member of IEEE.

\section{EVF 2019 - Panel discussion - Intervention of Mohit Dubey (CEO, Atal Incubation Centre @MIT ADT University)}

In September 2015, the General Assembly adopted the 2030 Agenda for Sustainable Development that includes 17 Sustainable Development Goals (SDGs). Building on the principle of "leaving no one behind", the new Agenda emphasizes a holistic approach to achieving sustainable development for all.

Given the urgency and need for Actions to achieve SDGs by 2030, a new beginning is required. A new world order should be built by our partnerships to address some of the key challenges faced by billions of people. As a key take away from the EVF discussions and putting them against the SDGs backdrop, we should focus on building programs for:

\section{$\checkmark$ SDG 4: Quality Education \\ $\checkmark$ SDG 8: Decent Work and Economic Growth \\ $\checkmark$ SDG 11: Sustainable Cities and Communities \\ $\checkmark$ SDG 17: Partnerships for the Goals}

As MIT ADT University, Pune (India) provided a platform to deliberate upon the contours of the action item; I have below suggestions to work for the above SDGs:

1. Set up a Multi Skill Development Centre (MSDC) with Centre of Excellence (CoE) approach for various domains for eg; climate change, renewable energy (Solar, Wind), cultural exchange

2. Mentoring programs for students to orient them for career pathways across two countries based on the skills acquired

3. Research partnership leading to Innovation and Venture Development opportunities at Incubator

4. Annual Dialogue between Academia, Industry and Government partners of both countries 
While we all agreed the need and pivotal role of ecosystem with both local and Global players, India presents a huge opportunity given the volume of young graduates (8 million every year). We should put together the systems where the energy of these youngsters can be channelized in the right direction. With a huge network of 900+ Universities and 40,000 colleges, India has a potential to transform these youths into 'Skill Capital' for the World.

Govt. of India has recently launched several programs like Skill India, Smart Cities, Digital India, Atal Innovation Mission (AIM), Make in India, Clean India Mission etc with huge potential. Hence over the next decade if the French partners can bring the Technological wisdom and Financial support to India, I'm sure the Indian Academia, Corporate and Government partners are ready to play their part in creating World class Solutions for the World.

\section{Dr. Mohit Dubey CEO, AIC-MIT ADT Incubator Forum}

